\title{
Alteration of gap junctions and connexins in the right atrial appendage during cardiopulmonary bypass
}

\author{
Hung-I Yeh, MD, PhD, ${ }^{a}$ Shou-Hsien Hou, MD, ${ }^{a}$ Hsiang-Rui Hu, BSc, ${ }^{a}$ Yi-Nan Lee, MS, ${ }^{a}$ Jiun-Yi Li, MD, ${ }^{a}$ \\ Emmanuel Dupont, PhD, ${ }^{c}$ Steven R. Coppen, PhD, ${ }^{\mathrm{c}}$ Yu-Shien Ko, MD, PhD, ${ }^{\mathrm{b}}$ Nicholas J. Severs, PhD, DSc, ${ }^{\mathrm{c}}$ and \\ Cheng-Ho Tsai, MD
}

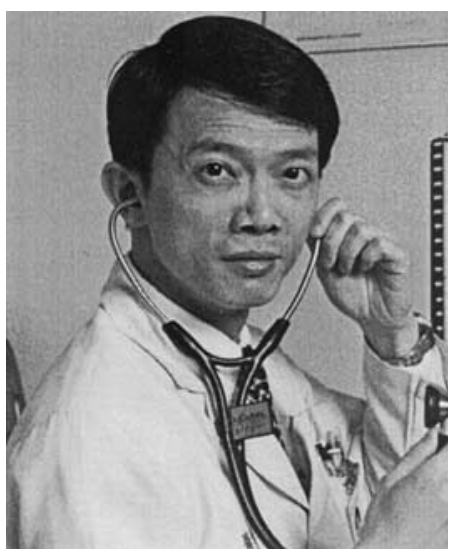

Dr Yeh
From the Departments of Cardiac Medicine and Medical Research, Mackay Memorial Hospital, Taipei Medical University, ${ }^{\mathrm{a}}$ and the First Cardiovascular Division, Department of Internal Medicine, Chang Gung Memorial Hospital, ${ }^{\text {b Taipei, Taiwan, and }}$ the National Heart and Lung Institute, Imperial College, London, United Kingdom. ${ }^{\mathrm{c}}$

Supported by grants CCF-98-03 and 99-06 from the Cardiac Children Foundation, Republic of China, and MMH-8702 from the Medical Research Department of the Mackay Memorial Hospital, Taiwan. N.J.S acknowledges support from the European Commission (QLRT-1999-00516).

Received for publication Dec 26, 2001; revisions requested Jan 15, 2002; revisions received March 22, 2002; accepted for publication March 24, 2002.

Address for reprints: Hung-I Yeh, MD, Mackay Memorial Hospital, Cardiac Medicine, 92, Section 2, Chung-San North Rd, Taipei, Taiwan 10449.

J Thorac Cardiovasc Surg 2002;124: 1106-12

Copyright (C) 2002 by The American Association for Thoracic Surgery

0022-5223/2002 $\$ 35.00+0 \quad \mathbf{1 2 / 1 / 1 2 4 9 9 3}$

doi: $10.1067 / \mathrm{mtc} .2002 .124993$
Objectives: We investigated the influence of cardiopulmonary bypass on cardiomyocyte gap junctions and connexins.

Methods: Samples were collected at intervals during operation from the right atrial appendage in 21 patients (mean $[ \pm \mathrm{SD}]$ age $55 \pm 21$ years). Immunodetection of connexins was conducted by Western blotting and confocal microscopy with parallel electron microscopic examination of gap junctions.

Results: Downregulation of connexin 43 during the course of operation occurred in more than half of the patients. The mean densitometric value of connexin 43 decreased by $23 \%$, with samples from patients with coronary artery disease showing a greater reduction than seen in those from patients with other diseases $(31 \% \pm 22 \%$ vs $10 \% \pm 24 \%, P=.04)$. Such alterations were confirmed by confocal microscopy, which also demonstrated reduced connexin 45 immunolabeling in most patients. Electron microscopy revealed a reduction in the dimensions of cell membranelocated gap junctions and more frequent intracytoplasmic gap junctional membrane in samples from later time points $(P=.04)$.

Conclusions: Downregulation of connexins accompanied by a reduction in gap junctions is common in the cardiomyocytes of the right atrial appendage during cardiopulmonary bypass. The association of a marked reduction in connexin 43 with coronary artery disease may imply inadequate intraoperative cardiac protection in patients with this disease.

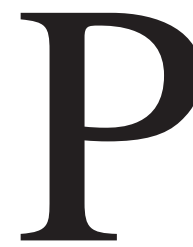

ropagation of action potentials between cardiomyocytes is mediated via gap junctions, constructed from connexin proteins. ${ }^{1}$ In human beings, the working atrial cardiomyocyte mainly expresses connexin (Cx) 40, Cx 43, and Cx 45. ${ }^{2}$ Physiologically, gap junctions are dynamic structures; the half-lives of the component connexins are reported to be between 1 and 3 hours. ${ }^{3,4}$ Thus, the expression and distribution of connexins may undergo alterations within short periods. Among factors affecting cardiac gap junctions, ischemia is known to have a profound effect. 5,6

In vitro studies have shown that several factors related to ischemia, such as elevated proton and decreased adenosine triphosphate levels, suppress gap junctional communication function..$^{7-9}$ Investigation of coronary artery disease (CAD) has also demonstrated that gap junction distribution and connexin expression in the ischemic zone are disturbed. ${ }^{5,6,10}$ This raises the possibility that cardiomyocyte gap junctions may change during cardiopulmonary bypass (CPB), when the heart faces a stress similar to the challenge of ischemia.

Although efforts have been introduced to ameliorate the ischemic insult during cardiac surgery (eg, application of hypothermia and cardioplegic solution ${ }^{11}$ ), the heart is not perfectly preserved, as is evident from the fact that more than $90 \%$ of patients display postoperative ventricular dysfunction. ${ }^{12}$ Another major factor affecting the clinical outcome, the occurrence of postoperative arrhythmia, ${ }^{13}$ is also 
TABLE 1. Clinical profiles and analysis of Cx43 and Cx40

\begin{tabular}{|c|c|c|c|c|c|c|}
\hline Patient No. & Age (y) & Sex & Diagnosis & CP & Cx43 (\%)* & Cx40 (\%)* \\
\hline 1 & 25 & $\mathrm{~F}$ & ASD & C & 86 & 74 \\
\hline 2 & 43 & $\mathrm{~F}$ & ASD, MVC & $B$ & 32 & 41 \\
\hline 3 & 16 & $M$ & ASD, MVC, VSD & $B$ & 97 & 73 \\
\hline 4 & 34 & $\mathrm{~F}$ & ASD, PAPVR & C & 104 & 20 \\
\hline 5 & 72 & M & Endocarditis & $B$ & 96 & 130 \\
\hline 6 & 43 & M & Mitral regurgitation & C & 93 & 103 \\
\hline 7 & 75 & M & Valvular aortic stenosis & $B$ & 109 & 44 \\
\hline 8 & 10 & M & VSD, PS & C & 102 & 72 \\
\hline 9 & 44 & $M$ & CAD (DVD) & $\mathrm{B}$ & 68 & 95 \\
\hline 10 & 43 & M & CAD (TVD) & $B$ & 48 & 109 \\
\hline 11 & 63 & $\mathrm{~F}$ & CAD (TVD) & $B$ & 102 & 141 \\
\hline 12 & 66 & $M$ & CAD (TVD) & $B$ & 74 & 58 \\
\hline 13 & 67 & $\mathrm{~F}$ & CAD (TVD) & $\mathrm{B}$ & 61 & 91 \\
\hline 14 & 70 & $\mathrm{~F}$ & CAD (TVD) & $B$ & 49 & 69 \\
\hline 15 & 71 & M & CAD (TVD) & $B$ & 53 & 97 \\
\hline 16 & 71 & $\mathrm{M}$ & CAD (TVD) & $B$ & 30 & 63 \\
\hline 17 & 72 & $\mathrm{~F}$ & CAD (TVD) & $B$ & 82 & 57 \\
\hline 18 & 78 & $\mathrm{~F}$ & CAD (TVD) & $B$ & 78 & 50 \\
\hline 19 & 78 & M & CAD (TVD) & $\mathrm{B}$ & 83 & 60 \\
\hline 20 & 46 & $M$ & CAD (TVD + LM) & $B$ & 110 & 118 \\
\hline 21 & 60 & $\mathrm{M}$ & CAD (TVD + LM) & $B$ & 64 & 137 \\
\hline
\end{tabular}

$A S D$, Atrial septal defect; $M V C$, mitral valve cleft; $V S D$, ventricular septal defect; $P A P V R$, partial anomalous pulmonary venous return; $P S$, pulmonary stenosis; $D V D$, double vessel disease; $T V D$, triple vessel disease; $L M$, left main artery disease; $C P$, type of cardioplegic solution; $C$, crystalloid, $1 L$ contains Na $120 \mathrm{mmol} / \mathrm{L}$, Cl $180 \mathrm{mmol} / \mathrm{L}, \mathrm{K} 36 \mathrm{mmol} / \mathrm{L}$, Ca $2.4 \mathrm{mmol} / \mathrm{L}, \mathrm{Mg} 32 \mathrm{mmol} / \mathrm{L}$, bicarbonate, $10 \mathrm{mmol} / \mathrm{L}$, albumin $1.25 \%$, mannitol $0.4 \%$, methylprednisolone 500 $\mathrm{mg} ; B, 1: 1$ mixture of blood and crystalloid.

*Percentage of the value of the total connexin amount of the latest sample against that of the initial one; see "Methods" section for definition of the direction of change of $\mathrm{Cx} 43$ and $\mathrm{C} \times 40$ between the initial and last sample.

related to the bypass procedure. ${ }^{11}$ Because coordination of contractile function between cardiomyocytes relies on gap junctions and disturbance of the connexins is reportedly linked to arrhythmogenesis, ${ }^{14}$ it is of interest to examine the influence of CPB on gap junctions and connexins. To this end, we set out to investigate the temporal expression pattern of cardiomyocyte gap junctions and connexins during the course of cardiac surgery.

\section{Methods}

\section{Samples}

Ethical approval was granted by the institutional review board of the Mackay Memorial Hospital, Taipei, Taiwan. Informed consent was obtained from each patient. The procedures followed were in accordance with institutional guidelines. Human heart samples were collected in the operating theater from patients undergoing cardiac surgery and were taken from the right atrial appendage bordering the inserted cannula linked to the extracorporeal oxygenator. The first sample was collected just before or within 5 minutes after initial infusion of cardioplegic solution. Subsequent samples, one for each time point, were taken at intervals of 20 to 40 minutes. For each patient, 2 to 3 samples were collected. Each sample, measuring about $8 \mathrm{~mm}^{3}$, was bisected or trisected and allocated for immunoblotting, immunolabeling, and in some cases also thin-section electron microscopy.

\section{Immunodetection of Cardiomyocyte Gap Junctions}

Anti-connexin antibodies. Two affinity-purified, well-characterized connexin isotype-specific polyclonal antibodies were used to detect Cx40 (raised in rabbits, Y21Y[R968]) and Cx45 (raised in guinea pigs, Q14E[GP42]). ${ }^{1,15,16}$ For Cx43, a mouse monoclonal antibody was purchased (CHEMICON International, Inc, Temecula, Calif).

Immunoblotting. Western blotting was conducted as described previously elsewhere. ${ }^{2}$ A $20-\mu \mathrm{g}$ aliquot of sample was loaded in each lane. The membranes were incubated for $60 \mathrm{~min}-$ utes with the anti-Cx43 (1:500) or anti-Cx40 (1:100) antibody, washed, and incubated with an alkaline phosphatase-conjugated secondary antibody (1:5000; Pierce Chemical Company, Rockford, Ill). The color reaction was carried out with nitro blue tetrazolium/5-bromo-1-chloro-3-indolyl phosphate (NTB/BCIP) solution (Pierce).

Immunolabeling. Cryosections $10 \mu \mathrm{m}$ thick were immunostained for each of the connexins, as described previously elsewhere. ${ }^{2}$ Immunostained samples were examined by confocal laser scanning microscopy with a Leica TCS SP (Leica, Heidelberg, Germany).

\section{Analysis}

Densitometric scanning and analysis were performed on immunoblots. For $\mathrm{Cx} 43$, bands of various phosphorylated forms in each sample were measured separately and the values were added together to represent the total amount. When the values of samples 
from the same patient differed by more than $10 \%$, the samples were considered different. The dimensions of gap junctions found in ultrastructural examination were also measured. For this purpose, 25 randomly selected fields from each sample, each of which possessed at least 1 gap junction, were recorded at $25,000 \times$ magnification. For each patient, 2 samples of different time points were examined. Mean $( \pm S D)$ values of the length of gap junctions per field were obtained for each sample. Data were compared statistically by the $t$ test.

\section{Results}

Samples were collected from 21 patients (age $55 \pm 21$ years, male/female ratio 13:8). The clinical profiles of these patients are summarized in Table 1.

\section{Analysis of Western Blots}

Alterations in Cx43 and Cx40 during the course of observation were found to occur in most patients (Figure 1), although the patterns of change differed between these two connexins. For $\mathrm{Cx} 43$, the total amount remained unaltered in 8 cases, whereas it decreased in the other 13 participants. As a whole, the mean value of total $\mathrm{Cx} 43$ signal of all participants decreased by $23 \%$ (Table 1). A conspicuous feature of the Cx43 Western blots was a variable degree of phosphorylation. For $\mathrm{Cx} 40$, in 12 patients later samples had lower Cx40 levels than did the initial samples, whereas in 5 patients the Cx40 levels at consecutive time points were similar. On the other hand, in 4 patients the later samples had higher Cx40 levels (Figure 1, B). These variable patterns may reflect the marked heterogeneity of $\mathrm{Cx} 40$ distribution that was apparent in the atrial samples.

Considering the relationship between the changes in the connexins and the clinical profiles, it was found that total Cx43 amount declined more in samples from patients with CAD than in those from other diseases $(31 \% \pm 22 \%$ vs $10 \%$ $\pm 24 \%, P=.04)$.

\section{Immunoconfocal Microscopy}

Cx43 was found abundantly and homogeneously distributed in samples taken at the initial time point (Figure 2, A). In the later samples, the expression of $\mathrm{Cx} 43$ remained similar in patients with consistent total Cx43 amount during the bypass, whereas the signal was unevenly decreased in patients showing a decline in total Cx43 amount (Figure 2, B). By contrast, $\mathrm{Cx} 40$ varied in abundance and distribution in all samples (Figure 2, $C$ and $D$ ), which made the comparison difficult between samples of different time points from each patient. For $\mathrm{Cx} 45$, although the signal was faint, the distribution and change resembled those of $\mathrm{Cx} 43$ in each patient (Figure 2, $E$ and $F$ ).

\section{Electron Microscopic Examination}

Ultrastructural examination, conducted in samples from 7 patients (cases 9, 10,11, 14, 17, 18, and 20), showed that gap junctions varied in location and morphologic characteristics, appearing as the typical linear structures incorporated into the cell membrane (Figure 3,A), as intracytoplasmic annular forms (Figure 3, $A$ and $B$ ), or as linear structures stacked in parallel within the cell (Figure 3, $C$ and $D$ ). The intracytoplasmic forms of later time points tended to have a less well-defined pentalaminar structure (Figure 3, $B-D$ ). Comparison of the cell membrane-located gap junctions between samples of different time points revealed that the initial samples had more gap junctions per field $(1.6 \pm 0.6$ vs $1.2 \pm 0.5, P=.11$ ) of significantly larger size (total gap junction length $600 \pm 338 \mathrm{~nm}$ vs $341 \pm 172 \mathrm{~nm}, P=.03$ ) than did the later time points. In contrast, the intracytoplasmic gap junctions were more numerous at the later time points $(0.1 \pm 0.1$ vs $0.3 \pm 0.2, P=.04)$.

\section{Discussion}

In this study, downregulation of gap junctions in the right atrial appendage was a common phenomenon during CPB. In addition, patients with $\mathrm{CAD}$ showed a particularly marked decline in $\mathrm{Cx} 43$. These findings suggest that the normal life cycle of cardiac gap junctions is disturbed during cardiac anesthesia.

During cardiac surgery under certain circumstances different portions of the heart are not equally well protected. For example, in the presence of CAD, the stenotic lesions impair the delivery of cardioplegic solution to its territory. This may explain the more marked reduction of $\mathrm{Cx} 43$ in our patients with CAD. It should also be borne in mind that during such operations, the right atrial appendage (the source of samples of this study), which is located in the upper part of the heart and directly exposed under the illuminating beam, may not be constantly immersed in the cooling solution. The possibility for local rewarming and less satisfactory preservation than occurs with other parts of the heart may exist, although whether as a result the atrial appendage is more vulnerable to connexin and gap junction alterations than other parts of the heart remains unclear.

The downregulation of $\mathrm{Cx} 43$ within a short time observed here by Western blotting and immunoconfocal microscopy is striking. The electron microscopic results explain how this process may be mediated. One mechanism for degradation of gap junctions involves first withdrawal of gap junctional membrane from the cell membrane into the cytoplasm, followed by proteolysis. ${ }^{4}$ Previous studies with thin-section electron microscopy have shown that internalized gap junctions (those removed from the cell membrane) have distinct morphologic characteristics, such as annular shapes and parallel membrane stacks. ${ }^{4,17}$ Our electron microscopic results showed that gap junctions possessing these characteristics were more frequently observed in samples from later time points, than in those from the initial ones, suggesting that withdrawal of gap junctions from the cell membrane is enhanced. This may also explain the highly 

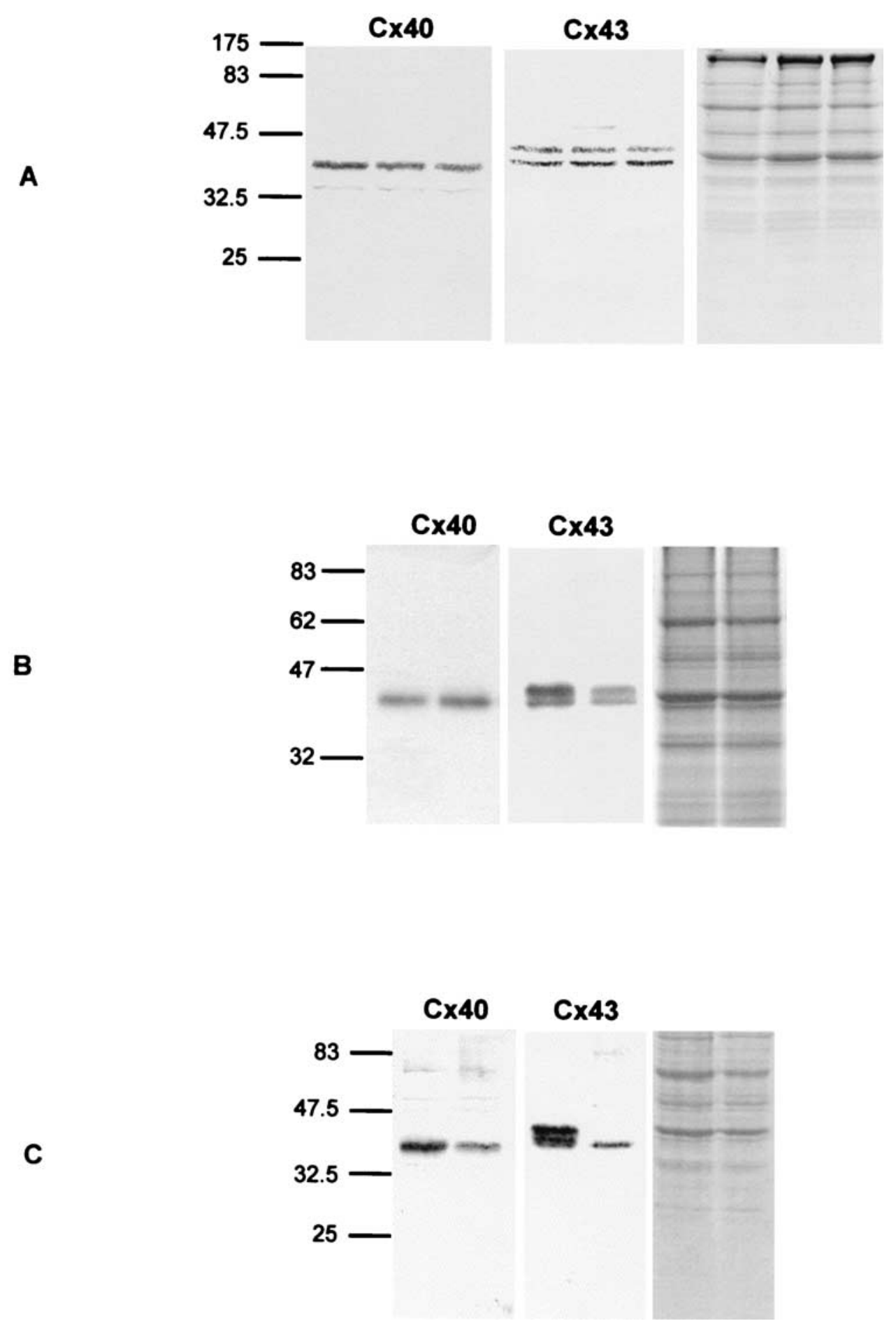

Figure 1. Analysis of connexin proteins by Western blotting. Lanes in each membrane, of which connexin detected is denoted at top, are arranged chronologically so that left is loaded with initial sample and right with last sample. A, In case 3, Cx40 follows stepwise decline from left to right. By contrast, both phosphorylated and nonphosphorylated forms of $\mathrm{Cx} 43$ in each lane possess similar density. B, In case 21, Cx40 is higher and Cx43 is lower at later time point. C, In case 2, lower levels of Cx40 and Cx43 are seen at later time point. Gel stained with Coomassie blue (right membranes) shows equal loading in each lane. 

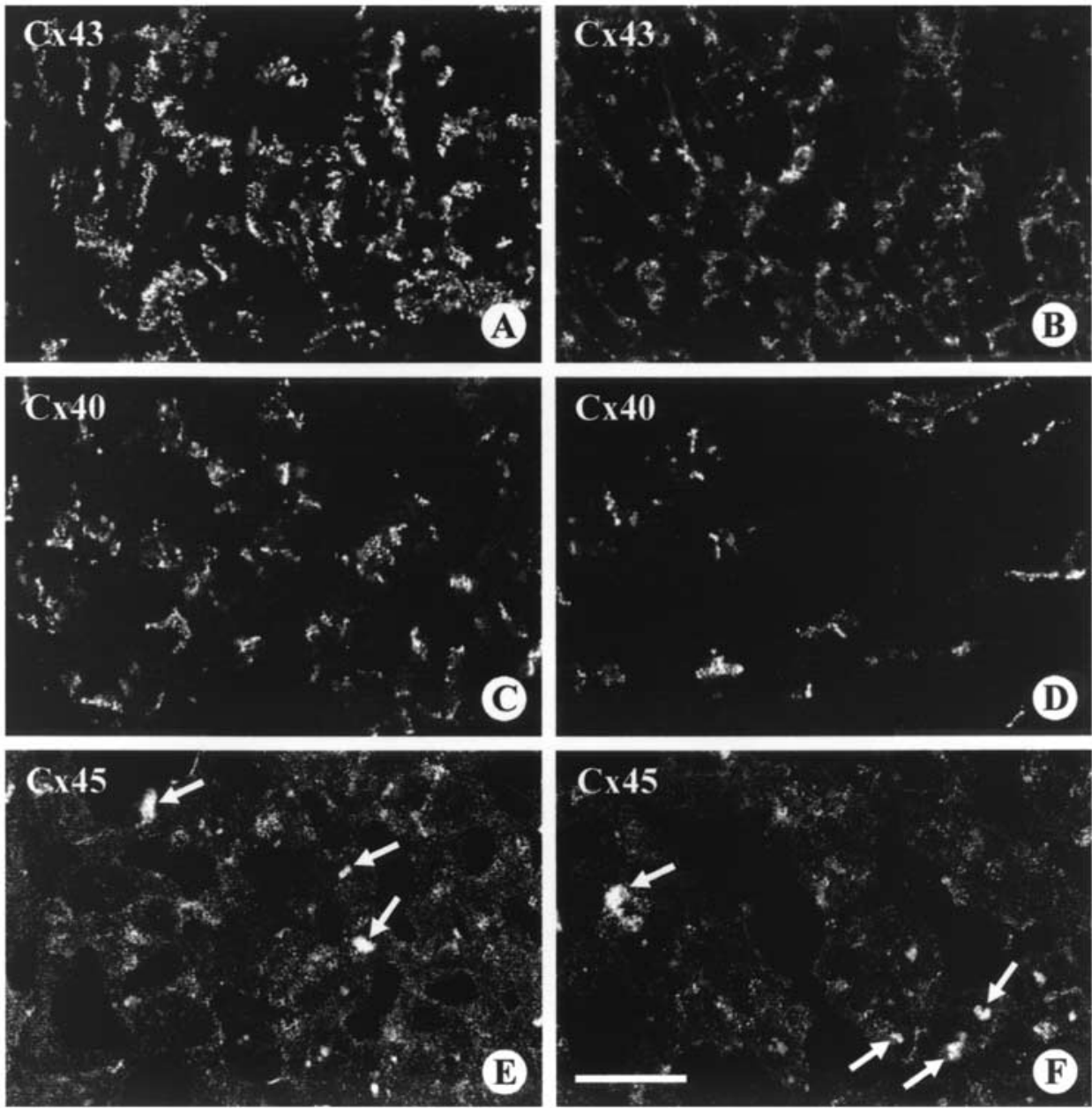

Figure 2. Immunoconfocal images demonstrating typical changes of expression of each connexin during CPB. Images on left are taken from samples of initial time point, whereas those on right are from latest time point. A and B, Images from case 10 demonstrate downregulation of Cx43 along course. C-F, Images from case 16 also demonstrate downregulation of $\mathrm{C} \times 40$ and $\mathrm{C} \times 45$ along course. Note autofluorescent spots from lipofuscin in images $E$ and $F$ because of enhanced laser power. Bar represents $30 \mu \mathrm{m}$. (Original magnification $\times 400$.)

variable degree of dephosphorylation of $\mathrm{Cx} 43$ observed in most samples, because removed gap junctions are likely to be targeted for degradation into the lysosomal compartment.

For $\mathrm{Cx} 45$, the small quantity of this connexin in the tissue precluded its detection with the Q14E(GP42) antibody by Western blotting; nevertheless, the immunoconfocal results show that reduction of $\mathrm{Cx} 45$ signal was common, as was seen for $\mathrm{Cx} 43$. On the other hand, unlike $\mathrm{Cx} 43$ or $\mathrm{Cx} 45, \mathrm{Cx} 40$ did not show an apparent reduction during the operation. It is important to bear in mind that $\mathrm{Cx} 40$ in the human atrial tissues is markedly heterogeneous in distribution, as observed in this and previous studies. ${ }^{16}$ Thus, data from small samples, such as those used in this study, may overestimate or underestimate the average content of $\mathrm{Cx} 40$, and the finding that the level of $\mathrm{Cx} 40$ expression apparently fluctuated during the bypass should be interpreted cautiously.

Downregulation of gap junctions and connexins during heart surgery may contribute to the cardiac depression observed in the initial postoperative period as a result of the lack of proper contractile coordination between individual myocytes as well as such other recognized contributors as inflammation triggered by reperfusion. ${ }^{18}$ This possibility depends on the quantity of gap junctional channels lost, the extent of cardiac muscle involved, and the recovery rates of connexin synthesis and gap junction formation. In addition, reports from connexin gene knockout studies and animal models of myocardial infarction indicate that reduced or heterogeneous expression of connexins provides a substrate for the development of arrhythmia. ${ }^{14,19}$ Furthermore, the 


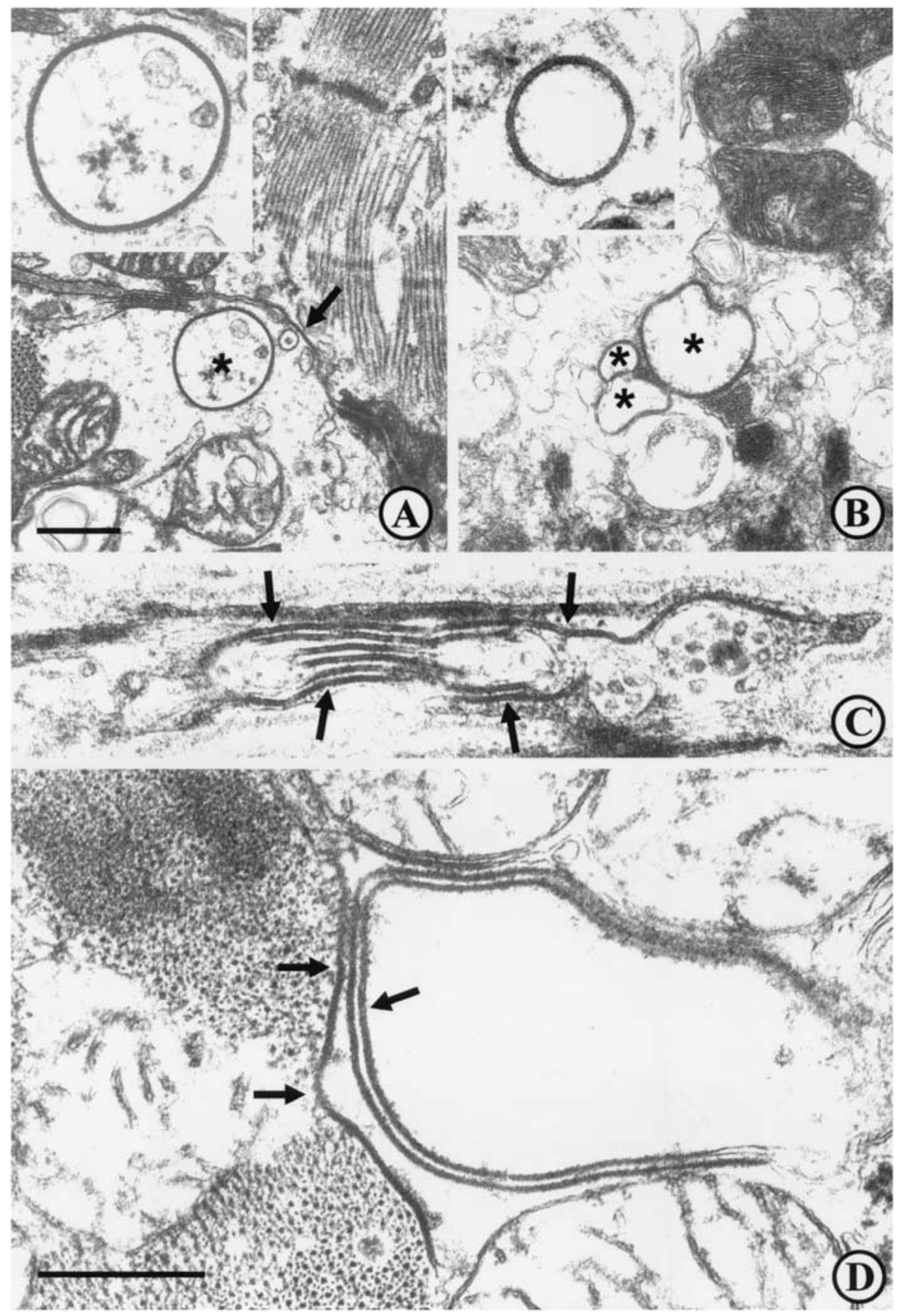

Figure 3. Thin-section electron micrographs demonstrating intracytoplasmic gap junctions in cardiac samples taken early (A) and late (B-D) during CPB. A, Case 10; annular gap junction (asterisk) is present adjacent to cell border where membrane bound gap junction (arrow) is situated. Inset shows enlarged view of annular gap junction with its characteristic pentalaminar structure. B, Case 17; cluster of three annular gap junctions (stars). Inset shows enlarged view of annular gap junction taken from another sample (case 9). C, Case 18; nine linear gap junctions of variable length stacked in parallel (between arrows). Note that pentalaminar morphology is less clearly defined but still can be recognized along portions of the junctions. D, Case 7; three linear gap junctions gather closely (between arrows). Images A and B are at the same magnification; Images C, D, and all the insets are at the same magnification. Bars represent $0.4 \mu \mathrm{m}$. (Original magnifications: $A$ and $B, \times 6000$; insets, $C$, and $D$, $\times 25,000$.) 
formation of scar tissues around the atriotomy site after operation affects action potential propagation. A multitude of factors thus may act in concert to lead to the onset of postoperative arrhythmia.

In conclusion, cardiomyocyte gap junctions and their component connexins in the right atrial appendage appear to be altered during CPB. Further investigation is required to clarify the clinical significance of our findings.

\section{References}

1. Severs NJ, Rothery S, Dupont E, Coppen SR, Yeh HI, Ko YS, et al. Immunocytochemical analysis of connexin expression in the healthy and diseased cardiovascular system. Microsc Res Tech. 2001;52:30122.

2. Vozzi C, Dupont E, Coppen SR, Yeh HI, Severs NJ. Chamber-related differences in connexin expression in the human heart. $J$ Mol Cell Cardiol. 1999;31:991-1003.

3. Darrow BJ, Laing JG, Lampe PD, Saffitz JE, Beyer EC. Expression of multiple connexins in cultured neonatal rat ventricular myocytes. Circ Res. 1995;76:381-7.

4. Laird DW. The life cycle of a connexin: gap junction formation, removal and degradation. J Bioenerg Biomembr. 1996;28:311-8.

5. Daleau P, Boudriau S, Michaud M, Jolicoeur C, Kingma JG. Preconditioning in the absence or presence of sustained ischemia modulates myocardial $\mathrm{Cx} 43$ protein levels and gap junction distribution. Can J Physiol Pharmacol. 2001;79:71-8.

6. Huang XD, Sandusky GE, Zipes DP. Heterogeneous loss of connexin43 protein in ischemic dog hearts. J Cardiovasc Electrophysiol. 1999;10:79-91.

7. Sugiura H, Toyama J, Tsuboi N, Kamiya K, Kodama I. ATP directly affects junctional conductance between paired ventricular myocytes isolated from guinea pig hearts. Circ Res. 1990;66:1095-102.
8. Firek L, Weingart R. Modification of gap junction conductance by divalent cations and protons in neonatal rat heart cells. $J$ Mol Cell Cardiol. 1995;27:633-43.

9. Duthe F, Dupont E, Verrecchia F, Plaisance I, Severs NJ, Sarrouilhe D, et al. Dephosphorylation agents depress gap junctional communication between rat cardiac cells without modifying the Connexin43 phosphorylation degree. Gen Physiol Biophys. 2000;19:441-9.

10. Peters NS, Green CR, Poole-Wilson PA, Severs NJ. Reduced content of connexin43 gap junctions in ventricular myocardium from hypertrophied and ischaemic human hearts. Circulation. 1993;88:864-75.

11. Dinardo JA. Myocardial preservation: In: Dinardo JA, editor. Anesthesia for cardiac surgery. Norwalk (CT): Appleton \& Lange; 1998. p. $349-64$.

12. Breisblatt WM, Stein KL, Wolfe CJ, Follansbee WP, Capozzi J, Armitage JM, et al. Acute myocardial dysfunction and recovery: a common occurrence after coronary bypass surgery. J Am Coll Cardiol. 1990;15:1261-9.

13. Tamis JE, Steinberg JS. Atrial fibrillation independently prolongs hospital stay after coronary artery bypass surgery. Clin Cardiol. 2000; 23:155-9.

14. Gutstein DE, Morley GE, Vaidya D, Liu F, Chen FL, Stuhlmann H, et al. Heterogeneous expression of gap junction channels in the heart leads to conduction defects and ventricular dysfunction. Circulation. 2001;104:1194-9.

15. Coppen SR, Dupont E, Rothery S, Severs NJ. Connexin45 expression is preferentially associated with the ventricular conduction system in mouse and rat heart. Circ Res. 1998;82:232-43.

16. Dupont E, Ko Y, Rothery S, Baghai M, Haw M, Severs NJ. The gap-junctional protein connexin40 is elevated in patients susceptible to postoperative atrial fibrillation. Circulation. 2001;103:842-9.

17. Severs NJ. Microscopy of the gap junction: a historical perspective. Microsc Res Tech. 1995;31:338-46.

18. Bolli R. Oxygen-derived free radicals and postischemic myocardial dysfunction. J Am Coll Cardiol. 1988;12:239-49.

19. Lerner DL, Yamada KA, Schuessler RB, Saffitz JE. Accelerated onset and increased incidence of ventricular arrhythmias induced by ischemia in Cx43-deficient mice. Circulation. 2000;101:547-52. 